\title{
RARE DISEASES, AN ANESTHETIC CHALLENGE. REPORT OF ONE CASE OF PHELAN-MCDERMID SYNDROME
}

Bragado Domingo Jo Rodríguez Rodríguez F. B.,Park J. Y., Calle Ortiz Mog ltza Barranco Mo, Ayala Ortega J.L. Hospital Rey Juan Carlos, Dept of Anaesthesiology \& Pain Medicine, Móstoles, Spain

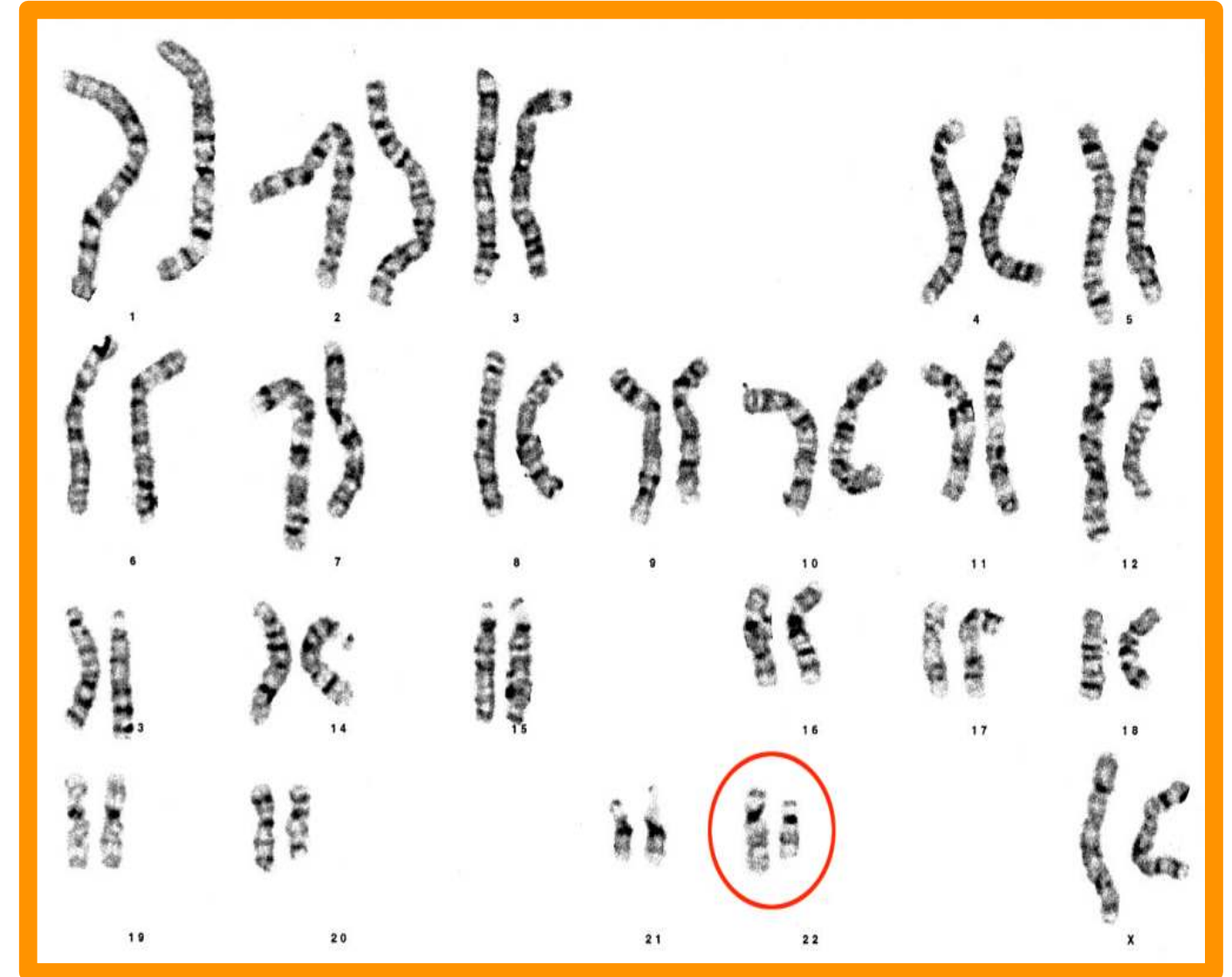

BACKGROUND:

Rare syndromes pose a challenge for the anesthetic management, since they are almost unknown diseases and it is rare to find them in the operation room. Most of them present symptoms in various organs and systems.

Phelan-McDermid syndrome is a contiguous gene disorder resulting from deletion of the distal long arm of the chromosome 22, which leads to the absence or mutation of the gene SHANK3.

This syndrome is characterized by neonatal hypotonia, normal growth, absent or delayed speech, moderate to profound developmental delay and minor dysmorphic features. Other common features are large fleshy hands, dysplastic toenails, lymphedema and decreased perception of pain.

\section{CASE REPORT:}

The aim of this poster is to share our experience in a case of a 17 years old woman with Phelan-McDermid Syndrome diagnosis, who underwent gastroscopy for episodes of cycling vomiting and weight loss in the last six months. Her personal history included a surgical of anomalous origin of the left coronary artery from the left pulmonary trunk.

The patient had a severe intellectual disability but collaborated well, so that a peripheral venous line could be inserted on right hand. Procedure was performed under sedation with very low doses of propofol (approximately I $\mathrm{mg} / \mathrm{kg}$ ), with very good tolerance on the part of the patient.

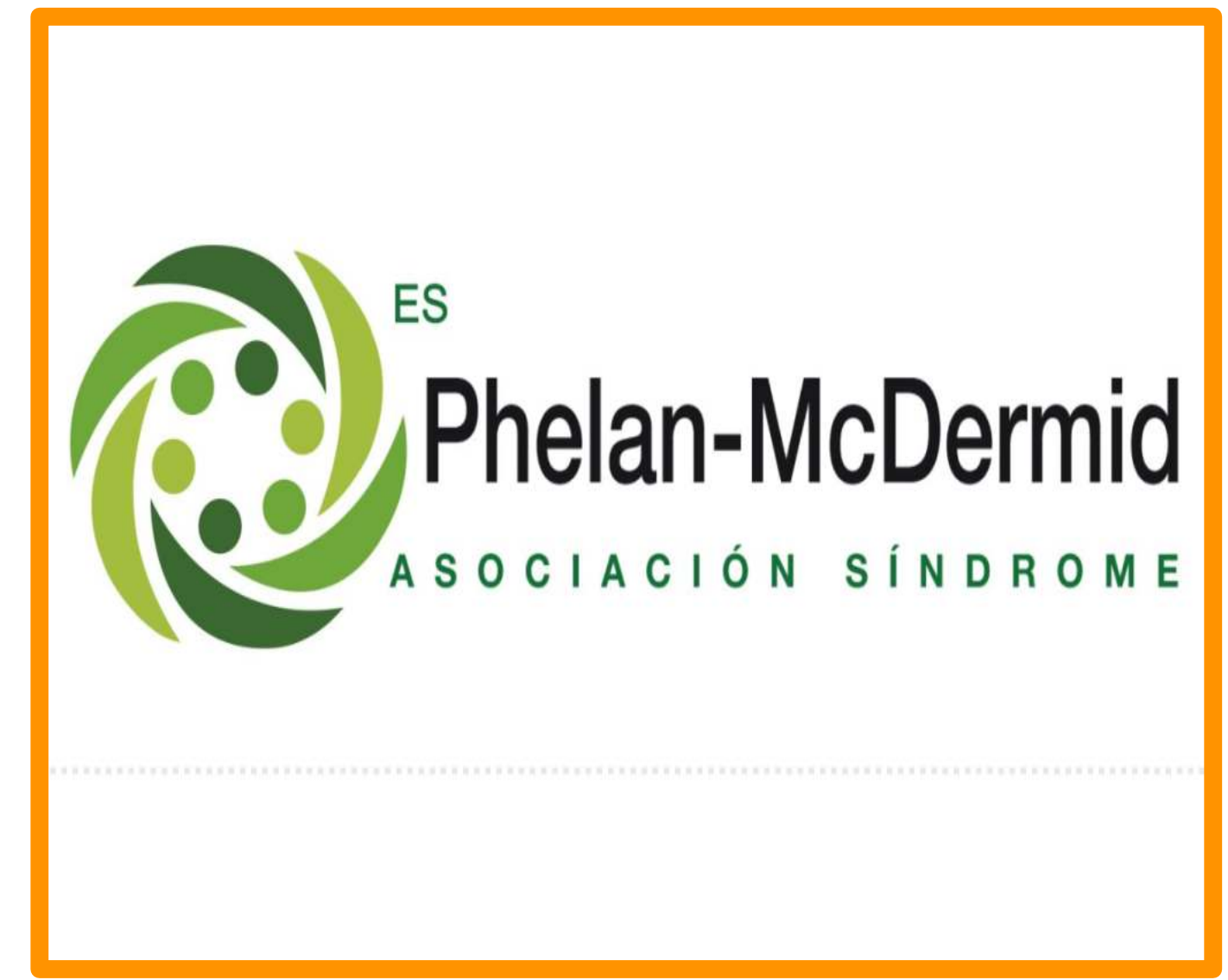

There were no respiratory complications or other incidences during gastroscopy, and the awakening of the patient ran without any problem.

Final diagnosis was erosive gastritis because of Helicobacter Pylori infection.

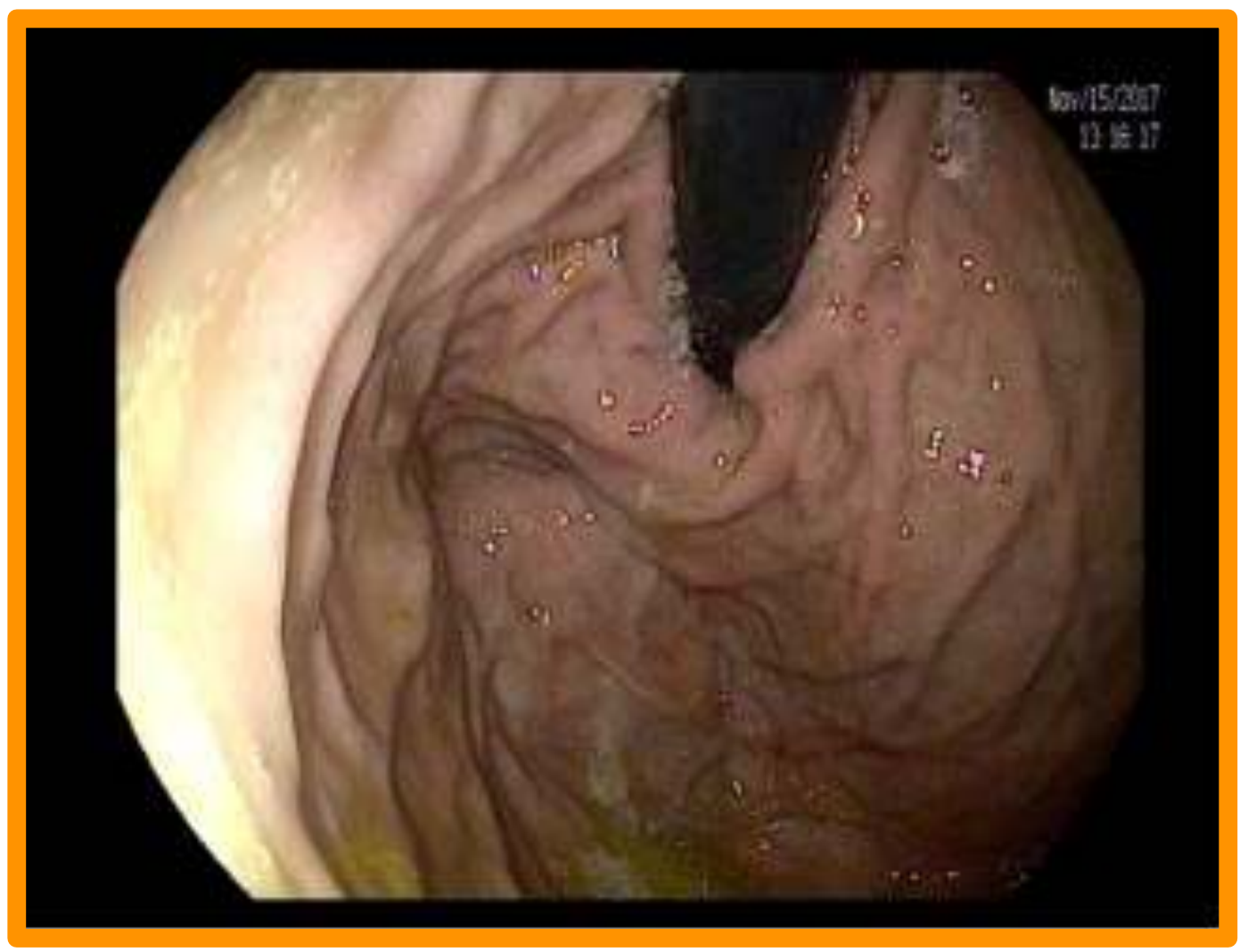

\section{DISCUSSION:}

Phelan-McDermid Syndrome, like other rare diseases, is a problem in routine clinical practise due to the low frecuency with which we find them in the operating room.

There are not many publications on this syndrome related on anaesthesia, so it is important to publicize this disease to perform a safe anesthetic practice.

Both inhalatory and intravenous anesthesias are safe techniques, and it is remarkable that these patients have a decreased perception of pain, so the doses of the administered drugs have to be adjusted.

\section{REFERENCES:}

K. Phelan, H. E McDermid. "The 22q I 3.3 Deletion Syndrome (Phelan-McDermid Syndrome)". Mol Syndromol. 2012 Apr; 2(3-5): I86-20I.

Asociación Española Phelan-McDermid. www.22q13.org.es 